\title{
Evaluation of circumsporozoite protein of Plasmodium vivax to estimate its prevalence in the Republic of Korea: an observational study of incidence
}

Pyo-Yun Cho ${ }^{1 \dagger}$, Sang-Wook Lee ${ }^{2 \dagger}$, Seong Kyu Ahn' ${ }^{1}$, Jin Su Kim', Seok Ho Cha ${ }^{3}$, Byoung-Kuk Na ${ }^{4}$, Yun-Kyu Park', Sung Keun Lee ${ }^{5}$, Won-Ja Lee ${ }^{6}$, Ho-Woo Nam7, Sung-Jong Hong ${ }^{8}$, Jhang Ho Pak', Yoon-Joong Kang ${ }^{10}$, Youngjoo Sohn ${ }^{11}$, Young-Yil Bahk ${ }^{12}$, Han-lk Cho ${ }^{13}$, Tong-Soo Kim ${ }^{1 *}$ and Hyeong-Woo Lee ${ }^{2^{*}}$

\begin{abstract}
Background: Plasmodium vivax re-emerged in 1993. Although the number of infections has been steadily decreasing, it is likely to continue to affect public health until it is eradicated. The aim of this study is to measure anti-circumsporozoite protein (CSP) antibody and compare malaria prevalence. As to understand the prevalence, an epidemiology study has to be conducted in the Republic of Korea.

Methods: A total of 1,825 and 1,959 blood samples were collected in 2010 and 2011, respectively, from the inhabitants of Ganghwa and Cheorwon counties. The antibody titers of the inhabitants were measured by enzyme-linked immunosorbent assay (ELISA) using recombinant protein purified from Escherichia coli transformed with a CSP gene-inserted pET-28a(+) expression vector. Microscopic examination was performed to identify malaria parasites.
\end{abstract}

Results: The annual parasite incidence (API) in Ganghwa decreased from 4.28 in 2010 to 2.23 in 2011, and that in Cheorwon decreased from 1.88 in 2010 to 1.15 in 2011. The antibody-positive CSP rate in these areas also decreased from 18.14\% (331/1825) in 2010 to 15.36\% (301/1959) in 2011. Pearson analysis showed a strong correlation between the API and the antibody-positive CSP rate in these areas $(r=1.000, P<0.01)$. The intensity of the immune responses of the inhabitants of Cheorwon, as measured by the mean optical density, decreased from $0.9186 \pm 0.0472$ in 2010 to $0.7035 \pm 0.0457$ in 2011 ( $P=0.034$ ), but increased in Ganghwa from $0.7649 \pm 0.0192$ in 2010 to $0.8237 \pm 0.1970$ in $2011(P=0.006)$. The immune response increased according to age $(r=0.686, P=0.041)$.

Conclusions: The positive CSP-ELISA rate was closely related to the API in the study areas. This suggests that seroepidemiological studies based on CSP-ELISA may be helpful in estimating the malaria prevalence. Moreover, such studies can be used to establish and evaluate malaria control and eradication programmes in high-risk areas in Korea.

\footnotetext{
*Correspondence: tongsookim@inha.ac.kr; rainlee67@naver.com

${ }^{\dagger}$ Equal contributors

'Departments of Parasitology, Inha University School of Medicine, Incheon 400-712, Republic of Korea

${ }^{3}$ Department of Parasitology and Institute of Health Sciences, Gyeongsang

University School of Medicine, Jinju 660-751, Republic of Korea

Full list of author information is available at the end of the article
}

\section{Biomed Central}

(c) 2013 Cho et al.; licensee BioMed Central Ltd. This is an Open Access article distributed under the terms of the Creative Commons Attribution License (http://creativecommons.org/licenses/by/2.0), which permits unrestricted use, distribution, and reproduction in any medium, provided the original work is properly cited. The Creative Commons Public Domain Dedication waiver (http://creativecommons.org/publicdomain/zero/1.0/) applies to the data made available in this article, unless otherwise stated. 


\section{Background}

Plasmodium vivax is the causative agent of relapsing benign tertian human malaria, the second most common type of human malaria, and it afflicts several hundred million individuals annually. This disease is a major public health problem in most tropical regions and many temperate countries, including the Democratic People's Republic of Korea (DPRK) and the Republic of Korea (ROK) [1].

The first scientific documentation of malaria occurrence was published in 1913, although malaria had been prevalent throughout the Korean peninsula for several centuries [2]. As a result of a national malaria eradication programme conducted in cooperation with the World Health Organization, the incidence of vivax malaria in ROK has rapidly decreased [3,4]. In fact, vivax malaria was thought to have been eradicated in ROK in the late 1970s until two sporadic cases were detected in the 1980s [5]. In 1993, one case was diagnosed in an ROK soldier serving in northern Gyeonggi province [6], and Cho et al. subsequently reported cases in two infected civilians [7]. Thereafter, many cases were reported near the demilitarized zone (DMZ), which centres on Paju-si, Yeoncheongun, Cheorwon-gun, Gimpo-si, Ganghwa-gun, Goyang-si, and Dongducheon-si. There is now considerable concern that malaria will become re-established in the region and then expand to other geographical areas [8].

Parasitaemia provides the basis for the classical method of measuring the endemicity of malaria. However, using data on only the incidence of parasitaemia may be insufficient to adequately determine the epidemiology of malaria in a given population. For example, when the incidence of malaria is low, mass blood surveys do not yield results commensurate with the work involved $[9,10]$. Serological surveys have provided valuable epidemiological information, especially in areas of low endemicity $[11,12]$. Interestingly, most patients with malaria in ROK show a long incubation period [13]. It is thought that a long incubation period is associated with sporogonic parasites; thus, circumsporozoite protein (CSP) was selected for the present seroepidemiological study. CSP is a sporogonic antigen and surface membrane protein that is expressed in all Plasmodium sporozoites. CSP has a central immunodominant region comprising a short tandem repeat of amino acid sequences containing multiple copies of the immunodominant B-cell epitope [14]. CSP is classified into two serotypes, VK210 [the dominant form, with GDRA(D/A)GQPA repeats] and VK247 [the variant form, with $\mathrm{ANGA}(\mathrm{G} / \mathrm{D})(\mathrm{N} / \mathrm{D}) \mathrm{QPG}$ repeats], which have different sequences in the repeated region of the CSP gene. It is known that the vivax malaria prevalent in Korea is the VK210 type [15].

The annual parasite incidence (API) in Ganghwa county (Figure 1A) fluctuated from 2001 to 2012 (from
0.76 to 3.36) and peaked in 2007 (Figure 2A). Two islands, Gyodongmyeon and Samsanmyeon, which contain $24.5 \%(15.1 \%-30.9 \%)$ of patients with malaria among all patients in Ganghwa with malaria, were selected for the seroepidemiological study to evaluate the CSP antigen. In Cheorwon (Figure 1B), four administrative areas were selected for blood collection. The API of Cheorwon also fluctuated during the same time period (from 0.12 to 4.07) and peaked in 2001 (Figure 2B). The number of patients with malaria was $9.9 \%(2.9 \%-22.5 \%)$ in Cheorwoneup, 33.5\% (20.4\%-44.7\%) in Dongsongeup, $12.6 \%(8.1 \%-16.7 \%)$ in Gimhwaeup, and $7.1 \%(0.0 \%-$ $12.7 \%$ ) in Seomyeon among all patients with malaria in Cheorwon county (Unpublished data, Korea Center for Disease Control and Prevention).

In this study, the dormant form of CSP was expressed and purified from Escherichia coli to produce antigen for the detection of anti-P. vivax CSP antibody levels in the inhabitants of Ganghwa and Cheorwon counties to evaluate CSP antigen in comparing the local malaria prevalence.

\section{Methods \\ Study area}

The study was conducted in Ganghwa county of Incheon Metropolitan city and Cheorwon county of Gangwon province, ROK. Ganghwa county (37 $31^{\prime}-45$ N', $125^{\circ} 33^{\prime}-126^{\circ} 2^{\prime} \mathrm{E}$ ) contains 179 villages (administrative village, -ri) in an area of $411 \mathrm{~km}^{2}$ that is covered with forested hilly mountains (181 $\left.\mathrm{km}^{2}, 44 \%\right)$, agricultural land $\left(164 \mathrm{~km}^{2}, 40 \%\right)$, building site $\left(13 \mathrm{~km}^{2}, 3 \%\right)$, and others $\left(52 \mathrm{~km}^{2}, 13 \%\right)$. The total population of Ganghwa county was 67,668 persons (male, 33,725; female, $38,943)$ living in 29,055 households in 2010 [16]. Cheorwon county $\left(38^{\circ} 05^{\prime}-24 \mathrm{~N}, 1^{\prime} 126^{\circ} 56^{\prime}-127^{\circ} 24^{\prime} \mathrm{E}\right)$ contains 109 villages (administrative village, -ri) in an area of $889 \mathrm{~km}^{2}$ that is covered with forested hilly mountains (601 km², 67\%), agricultural land (209 km², 24\%), building site $\left(8 \mathrm{~km}^{2}, 1 \%\right)$, and others $\left(71 \mathrm{~km}^{2}, 8 \%\right)$. The total population of Ganghwa county was 49,463 persons (male, 25,820; female, 23,643) living in 20,316 households in 2010 [17].

\section{Blood sample collection}

The study locations are shown on the map in Figure 1. All of the study areas were near the DMZ, which is located along the borderline of DPRK. Blood samples were collected from participants residing in 32 villages among two administrative areas in Ganghwa county of Gyeonggi province and in 10 villages among four administrative areas in Cheorwon county of Gangwon province. It was conducted in November and December of 2010 and in November and December of 2011 in two areas of ROK: Ganghwa county of Incheon city, which contains two islands, Gyodongmyeon and Samsanmyeon (Figure 1A), 

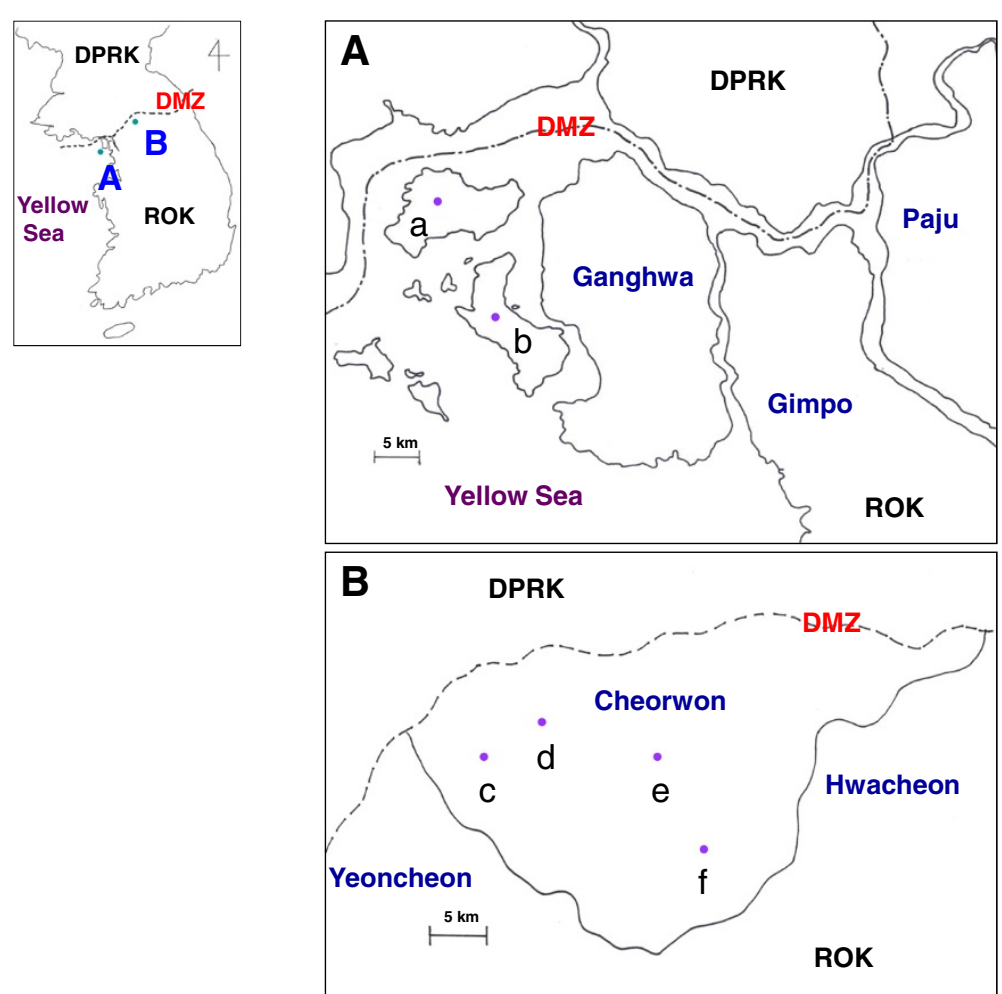

Figure 1 Study areas. A, Ganghwa county; B, Cheorwon county; a, Gyodongmyeon; b, Samsanmyeon; c, Cheorwoneup; d, Dongsongeup; e, Gimhwaeup; f, Seomyeon.

and Cheorwon county of Gangwon province, which contains 3 -eup and 1 -myeon, Cheorwoneup, Dongsongeup, Gimhwaeup, and Seomyeon which is connected to DPRK by land (Figure 1B). To evaluate CSP recombinant protein as antigen for serodiagnosis, a total of 1,825 (4.77\%) and $1,959(5.12 \%)$ blood samples were collected in 2010 and
2011 from who wanted be a volunteer, respectively, from 38,288 total inhabitants in the study areas.

Blood smears were prepared for microscopic examination. Sera were separated and stored at $-20^{\circ} \mathrm{C}$ for antibody analysis. Informed consent was obtained from all individuals. All samples were collected using human

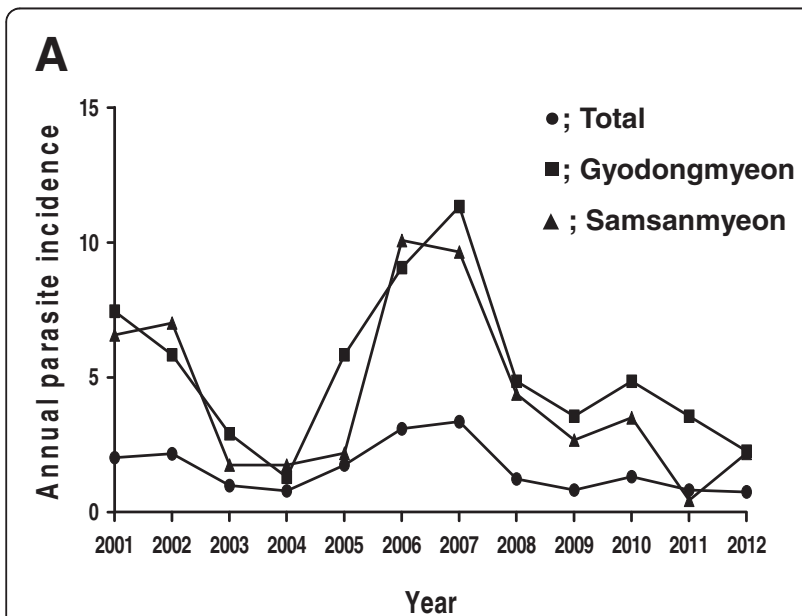

B

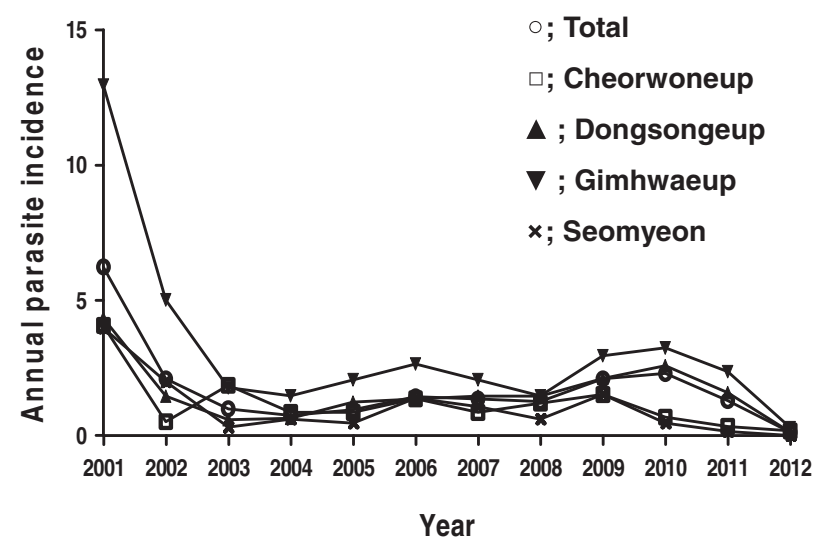

Figure 2 Annual parasite incidence of study areas from 2001 to 2012. A, Ganghwa county; B, Cheorwon county. 
protocols that were reviewed and approved by the Human Ethics Committee of Inha University

\section{Microscopic examination}

Thin blood films were prepared to determine the infectivity of blood samples. The blood films were fixed with methanol and stained with Giemsa stain diluted with buffered water at $\mathrm{pH} 7.2$ to emphasize the parasite inclusions in the red blood cells (RBCs). The fixed monolayer of $\mathrm{RBCs}$ in this procedure makes the morphological identification of the parasite to the species level much easier and provides greater specificity than that obtained with thick-film examination. Thin blood films are often preferred for routine estimation of parasitaemia because the organisms are easier to see and count with this method [18]. To estimate the densities of blood-stage parasites by microscopy, it was counted the number of asexual parasites observed relative to 200 white blood cells (WBCs) and then multiplied the parasite:WBC ratio by 8,000 , that is, the assumed number of WBCs per microlitre of blood [19].

\section{Amplification of the CSP gene}

To express the CSP gene, genomic DNA was extracted from the whole blood of a patient with malaria using a QIAamp Blood Kit (Qiagen, Hilden, Germany). Polymerase chain reaction (PCR) was performed using AccuPower PCR PreMix (Bioneer, Daejeon, Korea), $50 \mathrm{ng}$ of purified genomic DNA, and 40 pmoles each of forward (F1; 5'-CAC GTA GGA CAA AGT GCT AGC CG-3') and reverse primer (R1; 5-'ATG GAC TCC ATG CAG TGT AA-3'). The total volume was adjusted to $50 \mu \mathrm{l}$ with distilled water. The thermocycler conditions were as follows: denaturation at $94^{\circ} \mathrm{C}$ for 5 min; 35 cycles of $30 \mathrm{~s}$ at $94^{\circ} \mathrm{C}, 30 \mathrm{~s}$ at $55^{\circ} \mathrm{C}$, and $45 \mathrm{~s}$ at $72^{\circ} \mathrm{C}$; and finally, incubation at $72^{\circ} \mathrm{C}$ for $5 \mathrm{~min}$. All PCR products were analyzed on a $1 \%$ agarose gel, confirmed under a UV transilluminator, and purified with a NucleoSpin Extract Kit (Macherey-Nagel, Duren, Germany).

\section{DNA sequencing and analysis}

To genotype the CSP gene of $P$. vivax, the PCR product of the CSP gene was ligated into a pGEM-T Easy Vector (Promega, Madison, WI, USA) and transformed into E. coli $\mathrm{DH} 5 \alpha$. The PCR product containing E. coli DH5 $\alpha$ was selected on ampicillin-containing medium [20]. To confirm the transformants, gel electrophoresis was performed with EcoRI digestion products after the plasmid was prepared with a Qiagen plasmid isolation kit according to the protocol supplied by the manufacturer. The CSP gene sequence was determined using an ABI PRISM Dye Terminator Cycle Sequencing Ready Reaction Kit FS (Perkin Elmer, Cambridge, MA, USA) according to the manual supplied by the manufacturer.
M13 reverse and M13 forward (-20) primers were used in the sequencing. Nucleotide and deduced amino acid sequences were analyzed using EditSeq and Clustal in the MegAlign program, a multiple alignment program in the DNASTAR package (DNASTAR, Madison, WI, USA). The internet-based BLAST search program of the National Center for Biotechnology Information was used to search protein databases.

\section{Construction of the CSP expression vector}

To express the CSP gene in E. coli DH5 $\alpha$, a CSP gene fragment was amplified from a blood sample that was confirmed to be infected with the dormant type of P. vivax as described above with the exception of the addition of the Fex2 (5'-ggatccAAAAAGGATGGAAA GAAAG-3') and Rex2 (5'-aagcttGACTTTTCATTTGG GGCA-3') primers, which contain BamHI and HindIII sites on their $5^{\prime}$ ends, respectively. The amplified PCR products were digested with BamHI and HindIII, purified with a Qiagen gel extraction kit after being run on an agarose gel, and then integrated into the $B a m \mathrm{HI}$ and HindIII cleavage sites of the pET-28a(+) expression vector (Novagen, 5,369 bp). The resulting plasmid was subsequently used for the expression of a CSP-(His) ${ }_{6}$ fusion protein in E. coli. The transformants were confirmed by both gel electrophoresis of plasmid DNA after restriction enzyme digestion with BamHI and HindIII and DNA sequencing.

\section{Expression and purification of recombinant CSP}

Expression of the recombinant protein was induced in E. coli $\mathrm{DH} 5 \alpha$ with isopropyl-1-thio- $\beta$-D-galactopyranoside (IPTG) [10]. The CSP-(His) ${ }_{6}$ fusion protein was purified using immobilized metal ion affinity chromatography [21]. The purification was performed under native conditions according to the supplier's protocol (Novagen). Proteins were analyzed by sodium dodecyl sulfate polyacrylamide gel electrophoresis (SDS-PAGE) after each purification step.

\section{Western blot analysis}

The recombinant CSP-(His) ${ }_{6}$ fusion protein was separated on a $12 \%$ SDS-PAGE gel and transferred to a nitrocellulose membrane. After the transfer, the membrane was cut into strips and blocked for nonspecific binding with $3 \%$ skim milk for $12 \mathrm{~h}$ at $4^{\circ} \mathrm{C}$. The membrane was then washed three times for $10 \mathrm{~min}$ each with $0.15 \%$ Tween 20-PBS. The strips were allowed to react with sera from patients with malaria or from uninfected individuals (diluted $1: 100$, vol/vol) for $4 \mathrm{~h}$; they were then washed using the procedure described above. The membrane was subsequently incubated with diluted peroxidase-conjugated goat anti-human IgG secondary antibody (1:1,000, v/v) (Sigma) for $3 \mathrm{~h}$ at room temperature. For colour development, a 
solution containing $0.2 \%$ diaminobenzidine and $0.02 \%$ $\mathrm{H}_{2} \mathrm{O}_{2} / \mathrm{PBS}$ was applied to each well [22,23].

\section{Enzyme-linked immunosorbent assay}

Enzyme-linked immunosorbent assays (ELISAs) were used to determine whether the blood samples contained antibodies against the CSP VK210 of P. vivax. Briefly, the capture antigen solution $(50 \mathrm{ml}, 0.5 \mu \mathrm{g} / \mathrm{ml})$ was placed on a 96-well plate (Corning, Lowell, MA, USA) and incubated for $12 \mathrm{~h}$ at room temperature. The wells were aspirated and filled with blocking buffer (1\% BSA, $0.05 \%$ PBS-Tween 20) and incubated for $1 \mathrm{~h}$ at room temperature. After the wells were washed with $0.05 \%$ PBS-Tween 20 three times, human serum samples in blocking buffer at a dilution of 1:100 ( $\mathrm{vol} / \mathrm{vol}$ ) were added to the wells. Four positive and four negative control serum samples were also added to each plate. After $2 \mathrm{~h}$ of incubation at room temperature, the plates were washed with $0.05 \%$ PBS-Tween 20 three times, and peroxidase-conjugated anti-human IgG (Sigma, 1:2,000, $\mathrm{vol} / \mathrm{vol}$ ) diluted in blocking buffer was then added. The plates were re-incubated for $1 \mathrm{~h}$ at room temperature. The reaction was stopped by washing the plates as described above. To develop the colour, $100 \mu \mathrm{l}$ of 2.2' -azino-di-(3-ethyl-benzthiozoline-6-sulfonic acid) peroxidase substrate (Kirkegaard \& Perry Laboratories, Gaithersburg, MD, USA) was added, and the plates were incubated for $30 \mathrm{~min}$. Absorbance was measured at $405 \mathrm{~nm}$, and the cut-off value for positivity was defined as the mean +3 standard deviations of the negative control samples. Negative sera were collected from volunteers among the staff of the Korea National Institute of Health (KNIH).

\section{Calculation of the annual parasite incidence}

The annual parasite incidence (API) was calculated as the number of malaria-positive patients per 1,000 inhabitants for each of the study sites using microscopy: API $=$ (number of positive slides / total number of slides) $\times 1,000$.

\section{Data analysis}

The differences in the positive CSP rates between 2010 and 2011 were determined by a Mann-Whitney test. Data analyses were performed using GraphPad software (GraphPad Software Inc., La Jolla, CA, USA). Pearson's correlation analysis was performed to examine the relationship between seropositivity and the API of $P$. vivax in a given year. The data were analyzed using SPSS software, version 17.0 (SPSS Inc., Chicago, IL, USA). A $P$ value of $<0.05$ was considered statistically significant. The correlation sizes were interpreted as none (0.0-0.09), small (0.1-0.3), medium (0.3-0.5), or strong $(0.5-1.0)$ [24].

\section{Results}

DNA sequence of the VK210 Korean isolate

The CSP gene that was amplified by PCR from genomic DNA was analysed on a $1.0 \%$ agarose gel. Amplification of the CSP gene yielded an approximately 750-bp DNA fragment (Figure 3A) that, after purification, was ligated into the pGEM-T Easy vector. The transformants were confirmed to contain PCR inserts by EcoRI digestion. The plasmid containing the PCR product was named pCS210 and was used for DNA sequence analysis. DNA sequencing revealed that the cloned CSP gene was 717 bp long and comprised 239 amino acids that were identified by DNASIS. The nonapeptide repeat unit, located between Region I (KLKOP) and Region II (PCSVT), showed the sequence $\mathrm{GD}(\mathrm{N}) \mathrm{R}(\mathrm{G}) \mathrm{AD}(\mathrm{G} / \mathrm{A}) \mathrm{GQP}(\mathrm{A}) \mathrm{A}$ and was repeated 18 times.

\section{Expression and antigenicity of CSP VK210 type in E. coli}

To generate the expression plasmid, the repeat region of the CSP gene was amplified from patient genomic DNA, digested with BamHI and HindIII, and subcloned into the same restriction enzyme sites of expression vector pET-28a(+) (Figure 3B). The resultant plasmid, pCS210, contained the repeat region of the CSP gene fused to a (His) ${ }_{6}$-tag. The recombinant plasmid pCS210 was then transferred into E. coli DH5 $\alpha$. Next, $1 \mathrm{mM}$ IPTG was added to cultures of $E$. coli DH5 $\alpha$ (pCS210) grown to logarithmic phase in liquid LB plus $100-\mu \mathrm{g} / \mathrm{ml}$ ampicillin to induce expression of the target protein. SDS-PAGE followed by Coomassie blue staining showed that the molecular weight of the CSP recombinant protein was $45 \mathrm{kDa}$ under native purification conditions (Figure 4A). The molecular weight of the target protein was twice as large as the expected molecular weight $(24 \mathrm{kDa})$, which had been determined by DNASIS, it may affected by the repeated region of CSP.

The antigenicity of the CSP recombinant protein was determined by western blot. The sera of patients with malaria reacted positively (Figure $4 \mathrm{~B}$ ). To determine the sensitivity and specificity of the CSP recombinant protein by ELISA, the sera of patients with malaria, which had been reserved in $\mathrm{KNIH}$ after collection between 2009 and 2010, were used. Sera from 15 of 51 patients with malaria (sensitivity, 29.4\%) were positive, while one serum sample from the normal control group $(n=10)$, who had never been exposed to malaria, was positive (specificity, 90.0\%) (Figure 5).

\section{Local malaria transmission in Ganghwa}

Two large islands located west of Ganghwa, Gyodongdo island (Gyodongmyeon) and Seokmodo island (Samsanmyeon), were also surveyed (Figure 1A). A total of 230 of $1,235(18.62 \%)$ and 256 of 1,348 study subjects (18.99\%) showed a positive response on CSP-ELISA in 

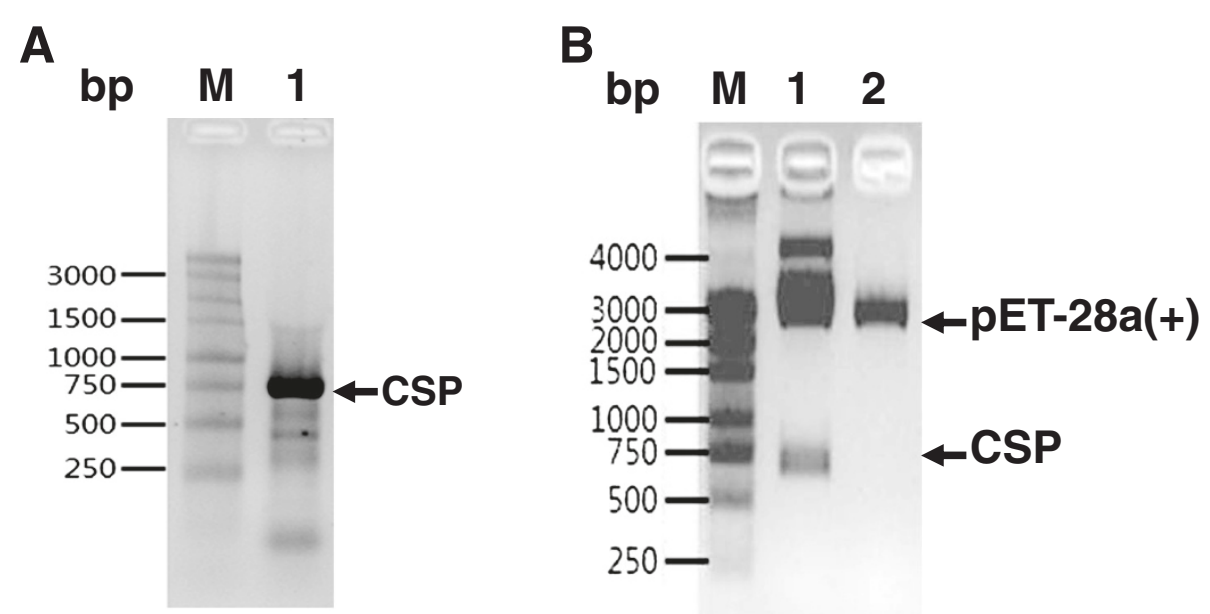

Figure 3 Genetic cloning of circumsporozoite protein gene. (A) Conformation of the PCR product of the circumsporozoite protein gene of Plasmodium vivax Korean isolate. M, Molecular size marker; lane 1, CSP gene. (B) Confirmation of circumsporozoite protein gene in Escherichia coli DH5a by restriction enzyme digestion with BamHI and HindIII. M, Molecular size marker; lane 1; BamHI and HindIII digested plasmid; lane 2, undigested plasmid.

2010 and 2011, respectively (Table 1). But there was no positive in microscopic examinations.

Gyodongmyeon displayed a higher positive rate in $2010(21.01 \%, 196 / 933)$ than in $2011(18.53 \%, 179 / 966)$. However, Samsanmyeon had a higher positive rate in $2011(20.12 \%, 77 / 382)$ than in $2010(11.26 \%, 34 / 302)$. The API for 2010 (4.28) was higher than that for 2011 (2.23). The APIs for 2010 (4.86) and 2011 (3.56) in Gyodongmyeon were higher than those for 2010 (3.50) and 2011 (0.44) in Samsanmyeon. The seropositivity of CSP in 2010 showed a strong positive linear relationship with the APIs of 2010 and $2011(\mathrm{r}=1.000, P<0.01)$. However, the seropositivity of CSP in 2011 showed a strong negative linear relationship with the APIs of 2010 and 2011 $(\mathrm{r}=1.000, P<0.01)($ Table 1$)$.

\section{Local malaria transmission in Cheorwon}

A total of 101 of 590 (17.12\%) and 45 of 611 (7.36\%) study subjects in Cheorwon (Figure 1B) showed a positive response on CSP-ELISA in 2010 and 2011, respectively (Table 2). But there was no positive in microscopic examinations. Interestingly, Gimhwaeup exhibited a 50\% (35/70) CSP-ELISA positive rate in 2010, but this rate dropped to $3.08 \%(2 / 65)$ in 2011. In 2010, the second
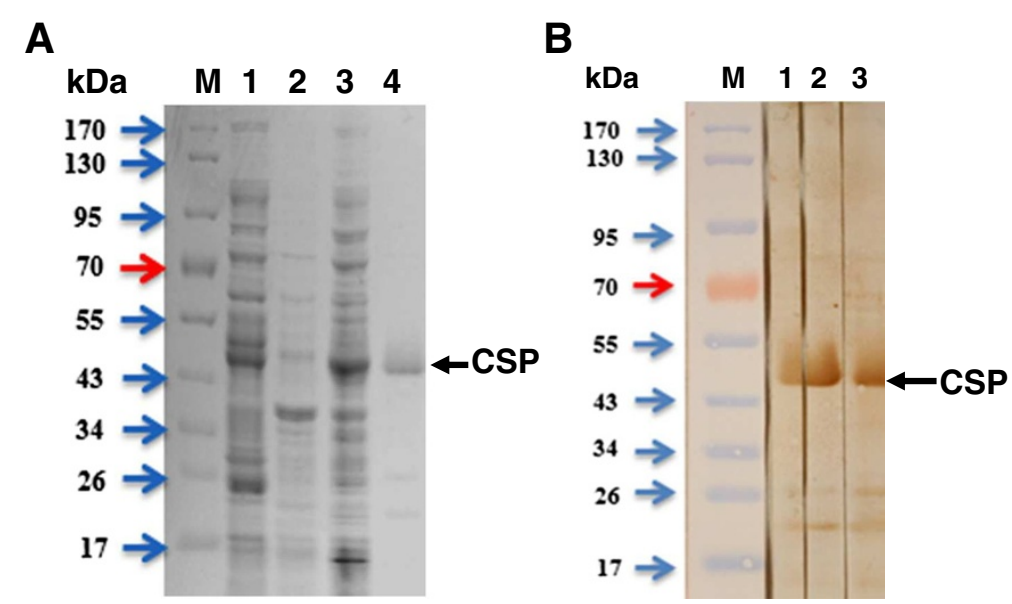

Figure 4 Expression of circumsporozoite protein gene in E. coli. (A) Purification of recombinant circumsporozoite protein with Ni-NTA agarose affinity chromatography. Lane M, Molecular weight protein marker; lane 1, induced E. coli DH5a cell lysate with IPTG; lane 2, flow-through; lane 3, wash; lane 4, elute. (B) Western blot analysis of recombinant circumsporozoite protein. M, Molecular weight protein marker; lanes 1-3, patients with malaria. 


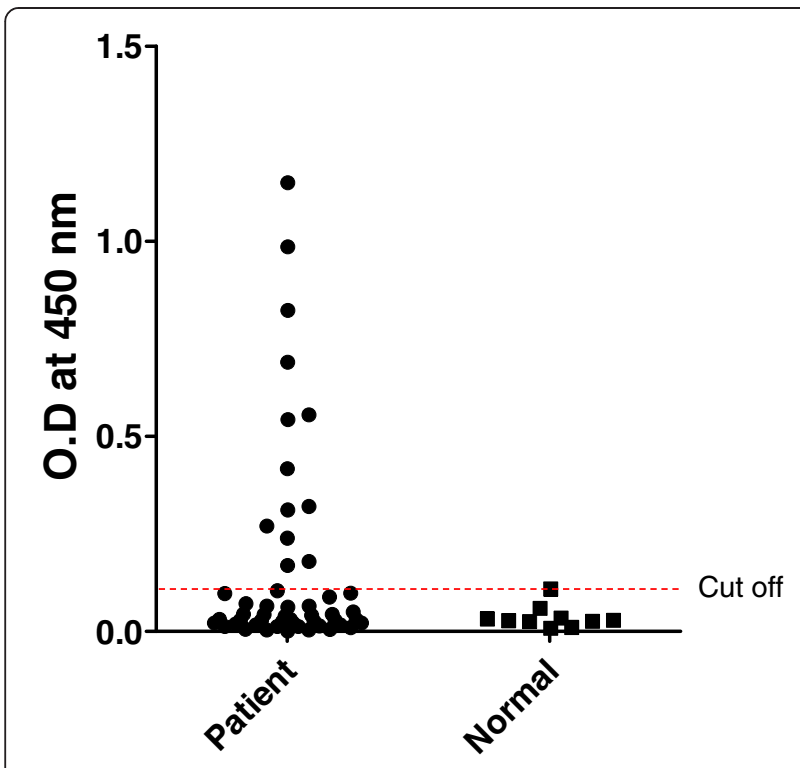

Figure 5 Antigenicity of recombinant circumsporozoite protein. Patient, individual infected with Plasmodium vivax; Normal, healthy volunteers.

highest positive rate $(31.51 \%, 23 / 73)$ occurred in Seomyeon, adjacent to the eastside of Gimhwaeup; this location was ranked highest in $2011(15.00 \%, 6 / 40)$. The third highest positive rate in both 2010 (10.85\%, 28/258) and $2011(6.08 \%, 20 / 329)$ was found in Dongsongeup, adjacent to the west side of Gimhwaeup. The lowest positive rate $(7.94 \%, 15 / 189)$ occurred in Cheorwoneup, to the far west of Cheorwon, in 2010; however, this location had the second highest rate in 2011. In addition, Gimhwaeup showed the highest APIs in both 2010 and 2011 (3.24 and 2.36, respectively). These results suggest that Gimhwaeup, located in the centre of Cheorwon, was the focus of malaria transmission during the study period. The seropositivity of CSP in 2010 showed a moderately positive linear relationship with the API of $2010(r=0.435)$ and strong positive relationship with the API of $2011(\mathrm{r}=0.509)$, but without statistical significance $(P=0.565, P=0.491$, respectively). However, the seropositivity of CSP in 2011 showed a strong negative linear relationship with the APIs of $2010(\mathrm{r}=-0.926)$ and $2011(\mathrm{r}=-0.931)$, but again without statistical significance $(P=0.071, P=0.069$, respectively) (Table 2 ).

\section{Intensity of immune responses}

The mean response intensity among 101 positive samples obtained from 590 inhabitants of Cheorwon in 2010 was $0.9186 \pm 0.0472$. This rate dropped to $0.7035 \pm 0.0457$ among 45 positive samples obtained from 611 inhabitants of Cheorwon in $2011(P=0.006)$ (Figure 6A). However, this rate did not change significantly in Ganghwa, increasingly slightly from $0.7649 \pm 0.0192$ among 230 positive samples obtained from 1,235 inhabitants in 2010 to $0.8237 \pm 0.1970$ among 256 positive samples obtained from 1,348 inhabitants in $2011(P=0.034)$ (Figure 6B). It should be noted that the study areas in Ganghwa were islands, and malaria transmission thus might not have been affected by foreign factors, whereas Cheorwon may have been affected by transmission from DPRK.

A total of 632 of 3,784 inhabitants exhibited a positive CSP response, and 625 of 632 positive cases could be categorized by age. Group A comprised CSP-positive inhabitants under 10 years of age who exhibited an immune response intensity of $0.7840 \pm 0.0044$. Group B comprised individuals between 11 and 20 years of age who exhibited an immune response intensity of $0.6974 \pm 0.0435$. Group C comprised individuals between 21 and 30 years of age who exhibited an immune response intensity of $0.7028 \pm 0.0300$. Group D comprised individuals between 31 and 40 years of age who exhibited an immune response intensity of $0.7730 \pm 0.0375$. Group E comprised individuals between 41 and 50 years of age who exhibited an immune response intensity of $0.7270 \pm 0.0347$. Group F comprised individuals between 51 and 60 years of age who exhibited an immune response intensity of $0.8272 \pm 0.0379$. Group G comprised individuals between 61 and 70 years of age who exhibited an immune response intensity of $0.7953 \pm 0.0253$. Group $\mathrm{H}$ comprised individuals between 71 and 80 years of age who exhibited an immune response intensity of $0.8435 \pm 0.0264$. Finally, Group I comprised individuals over 81 years of age who exhibited an immune response intensity of $0.8166 \pm 0.0409$. A strong positive correlation was shown between immune response and age $(\mathrm{r}=0.686, P=0.041)$ (Table 3).

\section{Discussion}

Our malaria research team is interested in diagnosing vivax malaria based on antibody detection. Although

Table 1 Positive rates of circumsporozoite protein and annual parasite incidence in Ganghwa

\begin{tabular}{|c|c|c|c|c|c|c|c|c|}
\hline \multirow[t]{2}{*}{ Area } & \multicolumn{2}{|c|}{ No. of sera tested } & \multicolumn{2}{|c|}{ No. of positive sera } & \multicolumn{2}{|c|}{ Positive rate (\%) } & \multicolumn{2}{|c|}{$\mathrm{API}^{\mathrm{a}}$} \\
\hline & 2010 & 2011 & 2010 & 2011 & 2010 & 2011 & 2010 & 2011 \\
\hline Gyodongmyeon & 933 & 966 & 196 & 179 & 21.01 & 18.53 & 4.86 & 3.56 \\
\hline Samsanmyeon & 302 & 382 & 34 & 77 & 11.26 & 20.12 & 3.50 & 0.44 \\
\hline Total & 1235 & 1348 & 230 & 256 & 18.62 & 18.99 & 4.28 & 2.23 \\
\hline
\end{tabular}

${ }^{a} A P I ;$ Annual parasite incidence. 
Table 2 Positive rates of circumsporozoite protein and annual parasite incidence in Cheorwon

\begin{tabular}{|c|c|c|c|c|c|c|c|c|}
\hline \multirow[t]{2}{*}{ Area } & \multicolumn{2}{|c|}{ No. of sera tested } & \multicolumn{2}{|c|}{ No. of positive sera } & \multicolumn{2}{|c|}{ Positive rate (\%) } & \multicolumn{2}{|c|}{$\mathrm{API}^{\mathrm{a}}$} \\
\hline & 2010 & 2011 & 2010 & 2011 & 2010 & 2011 & 2010 & 2011 \\
\hline Cheorwoneup & 189 & 177 & 15 & 17 & 7.94 & 9.60 & 0.68 & 0.34 \\
\hline Dongsongeup & 258 & 329 & 28 & 20 & 10.85 & 6.08 & 2.58 & 1.58 \\
\hline Gimhwaeup & 70 & 65 & 35 & 2 & 50.00 & 3.08 & 3.24 & 2.36 \\
\hline Seomyeon & 73 & 40 & 23 & 6 & 31.51 & 15.00 & 0.46 & 0.15 \\
\hline Total & 590 & 611 & 101 & 45 & 17.12 & 7.36 & 1.88 & 1.15 \\
\hline
\end{tabular}

${ }^{\mathrm{a} A P I}$; Annual parasite incidence.

microscopic examination is the gold standard method for malaria diagnosis worldwide, it has disadvantages, including the need for trained experts, its time-consuming nature, and its tendency to miss cases of low parasitaemia levels. However, antibody detection can compensate for the disadvantages of microscopic examination. If an antibody detection method is applied in the field using a rapid diagnostic test kit, the method can be used without rigorous training and the time required for diagnosis will be reduced. Furthermore, most patients with malaria have antibodies against malaria parasites, even those with low parasitaemia levels, and this method can be applied on a large seroepidemiologic scale. In this study, the CSP of the vivax malaria antigen was used to seroepidemiologically evaluate its usefulness in understanding malaria transmission. The survey areas, Ganghwa and Cheorwon, are two re-emerging malarial outbreak areas in South Korea, and both areas are located within 10 to $15 \mathrm{~km}$ of the southern DMZ [8]. The incidence of malaria peaks in August after the rainy season and declines to baseline by the end of October. Therefore, blood collection was carried out between November and December, when the active anopheline population was diminished. The DMZ is a 4-km-wide, 250-km-long corridor that extends across the middle part of the Korean peninsula. No civilians have been allowed to enter the DMZ for more than 50 years; therefore, natural ecosystems and biodiversity are highly conserved in the DMZ [25]. Outbreak areas have been expanding yearly both south and east of the DMZ. Outbreaks in these areas are believed to have originated from the northern part of the DMZ. The re-emergence of malaria is presumed to have originated not from the immigration of infected people from the north, but from mosquitoes infected with $P$. vivax that flew from the north because human passage through the DMZ is almost impossible (although there are some exceptions in the Gaeseong Industrial Zone). The corridor is heavily fortified on both sides of the buffer zones with land mines and barbed wire fences. Therefore, it is believed that these areas are exposed to mosquitoes. To estimate the prevalence of malaria exposure in these high-risk areas in Korea, CSP recombinant proteins were applied. It is a sporogony-stage protein that exists on the surface membrane of all plasmodium sporozoites. CSP has a central immunodominant region comprising short tandem repeat amino acid sequences that contain multiple copies of the immunodominant B-cell epitope [14]. Because it is highly immunogenic and can induce a protective response in sporozoite-immunized experimental animals and humans, CSP is being investigated as a candidate for a human malaria vaccine. The
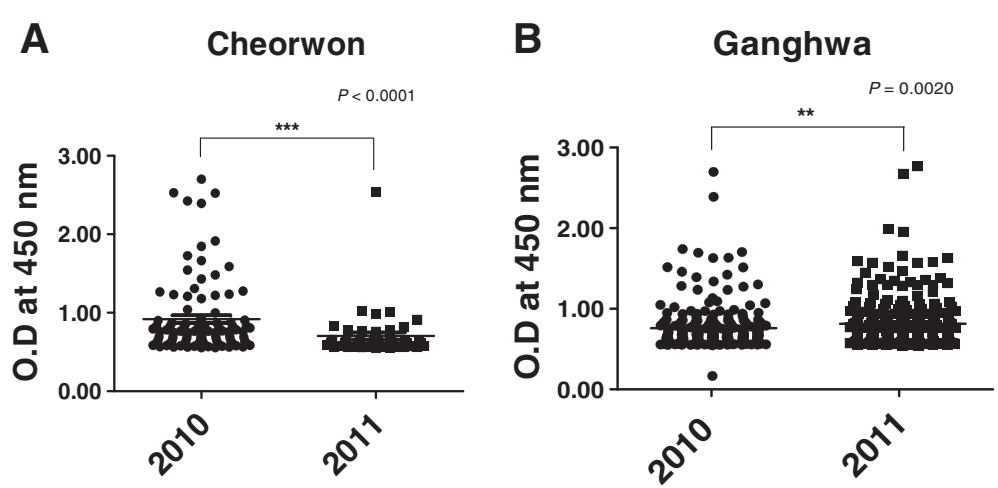

Figure 6 Comparison of immune responses to CSP between 2010 and 2011. Inhabitants of (A) Cheorwon and (B) Ganghwa. 


Table 3 The immune responses to CSP in inhabitants
according to age
\begin{tabular}{cccc}
\hline Group & Age & Optical density & Standard deviation \\
\hline A & $<10$ & 0.7840 & 0.0044 \\
B & $11-20$ & 0.6974 & 0.0435 \\
C & $21-30$ & 0.7028 & 0.0300 \\
D & $31-40$ & 0.7730 & 0.0375 \\
E & $41-50$ & 0.7270 & 0.0347 \\
F & $51-60$ & 0.8272 & 0.0379 \\
G & $61-70$ & 0.7953 & 0.0253 \\
H & $71-80$ & 0.8435 & 0.0264 \\
I & $80>$ & 0.8166 & 0.0409 \\
\hline
\end{tabular}

immunodominant B-cell epitopes of CSP from a large number of $P$. falciparum isolates of diverse geographical origins and of a smaller number of $P$. vivax isolates have been conserved within the species [26]. Interestingly, the lifespan of the CSP antibody in human beings is within 27 days in inhabitants of Thailand and is not boosted by additional exposure to CSP antigen, i.e., additional infection by anopheline mosquitoes [27]. These findings led us to consider patients with malaria with long incubation periods who usually show malaria onset the year following a five-month-long winter season without mosquitoes. Furthermore, the mean incubation period of $P$. vivax has been reported to be as long as $279 \pm 41$ days (range, 153-452 days) [28]. This finding suggests that patients with these long incubation periods could display either an absent or reduced antibody level against the CSP antigen. The percentages of patients with short and long incubation periods were $25 \%$ and $75 \%$, respectively [8]. However, it is possible that the patients with short incubation periods and an onset within 1 month after exposure to the CSP antigen delivered via infective anopheline mosquitoes had an elevated anti-CSP antibody level. This is why the CSP antigen was selected among the many possible malaria antigens. The hypothesis suggested by our malaria team is that the API of the relevant year includes patients with short incubation periods who were infected in the relevant year and patients with long incubation periods who were infected in the previous year. Therefore, the positive anti-CSP antibody rates were compared with the APIs for the relevant and subsequent years. The positive CSP-ELISA rate in 2010 was related to the 2010 malaria prevalence in Ganghwa and Cheorwon. This rate might be influenced by prevalence in patients with short incubation periods. The positive CSP-ELISA rate in 2010 was significantly related to the 2011 malaria incidence in Ganghwa and Cheorwon. This finding suggests that the malaria situation in the subsequent year can be predicted by the relevant positive CSP rate, and a portion of this rate might influence the incidence in patients with long incubation periods. In other words, the positive CSP rate could be considered to be the inoculation rate of sporozoites by infective vector mosquitoes. If a person is bitten by infective mosquitoes, he or she will show a positive response on CSP ELISA. However, it is very difficult to calculate how many individuals become patients after having been bitten by infective mosquitoes. This number is highly dependent on individual immune competency. Unfortunately, it was failed to identify parasite-positive inhabitants by microscopic examination of 632 CSP antibody-positive inhabitants. In addition, none of the CSP-positive individuals in 2010 become patients in 2011. However, the positive CSP antibody rate apparently affected the outbreak in the following year. This observation may indicate that the antibody-positive CSP rate is closely related to the community response rather than the individual response. However, in a preliminary study, the use of a blood antigen to detect an antibody with an indirect fluorescent antibody test (IFAT) showed that $16.67 \%(4 / 24)$ of individuals with IFAT seropositivity among inhabitants of Ganghwa became patients with malaria in the following year (authors' unpublished data). In another study performed in Gimpo in 1999, 16 of 125 individuals with IFAT seropositivity (12.80\%) were also positive for malaria by PCR detection. Blood samples with an antibody titer of $>1: 256$ had a high positive rate by PCR analysis [29]. Even if it is needed to obtain more data, the differences in PCR positive rates between CSP and IFAT among antibody-positive cases are attributable to different antigens, one from the sporogony stage (CSP) and the other from the schizogony stage (IFAT). These differences suggest that the stage-specific antigen and antibody detection methods should be matched. Therefore, it is better to use liver biopsy samples to detect parasites that are present in individuals with antibodypositive responses. Because the CSP antigen is a sporogony-stage antigen, it can be observed in the early developing stage of hypnozoites, which are liver-stage parasites. However, there are ethical and economic problems in obtaining the liver samples necessary to detect hypnozoites by PCR. Therefore, the positive responses on CSP antibody assays did not coincide with the PCR responses for antigen detection that used only blood samples.

To evaluate malaria transmission in a given geographical region, many factors, including temperature, mosquito density, vector capacity, climate, rainfall, and humidity, should be considered [30]. Parasitaemia provides a classical means of measuring malaria endemicity. However, patient incidence alone cannot provide a complete 
understanding of malaria prevalence because many factors affect the malaria prevalence in ROK, including the population density of mosquitoes, vectorial capacity, long- to short-incubation-patient ratio, symptomatic to asymptomatic patient ratio, differences in rainfall and temperature, and immunity of the community.

\section{Conclusions}

Antibody detection using CSP-ELISA may provide useful information regarding malaria prevalence in certain areas and individuals. These serological methods are useful in identifying areas that require malaria control and evaluating the surveillance system in certain areas.

\section{Competing interests}

The authors declare that they have no competing interests.

\section{Authors' contributions}

TSK, SHC, YS, HIC, BKN, and HWL conceived and designed the study and contributed to the execution of the research. HWL and TSK wrote the manuscript. YS, BKN, and WON performed the statistical analysis. SHC, JHP, WON, SJH, WJL, SKL, YKP, PYC, SKA, JSK, and YYB collected the blood samples. SHC, YJK, PYC, SJH, WJL, and JHP performed CSP-ELISA. SWL (Eastside High School) who has been working ay the University of Florida involved in expression of CSP recombitant protein and performed ELISA. HIC also provided most of research funding for this study. All authors have read and approved the final manuscript.

\section{Acknowledgments}

We are grateful to all blood donors and the staff of the Public Health Centres in Ganghwa and Cheorwon. This work was supported by the Korea Association of Health Promotion and Inha University Research Fund, 2012.

\section{Author details}

'Departments of Parasitology, Inha University School of Medicine, Incheon 400-712, Republic of Korea. ${ }^{2}$ Department of Pathology, Immunology, \& Laboratory Medicine, College of Medicine, University of Florida, J-566, 1275 Center Drive, Gainesville FL 32610, USA. ${ }^{3}$ Department of Biomedical Technology, Inha University School of Medicine, Incheon 400-712, Republic of Korea. ${ }^{4}$ Department of Parasitology and Institute of Health Sciences, Gyeongsang University School of Medicine, Jinju 660-751, Republic of Korea. ${ }^{5}$ Department of Pharmacology, Inha University School of Medicine, Incheon 400-712, Republic of Korea. ${ }^{6}$ Department of Parasitology, National Institute of Health, Osong 363-951, Republic of Korea. ${ }^{7}$ Department of Parasitology and Catholic Institute of Parasitic Diseases, College of Medicine, Catholic University of Korea, Seoul 137-701, Republic of Korea. ${ }^{8}$ Department of Medical Environmental Biology, College of Medicine, Chung-Ang University, Seoul 156-756, Republic of Korea. ${ }^{9}$ Asan Institute for Life Sciences, University of Ulsan College of Medicine, Asan Medical Center, Seoul 138-736, Republic of Korea. ${ }^{10}$ Department of Biomedical Science, Jungwon University, Goesan Chungbuk 367-805, Republic of Korea. ${ }^{11}$ Department of Anatomy, College of Korean Medicine, Institute of Korean Medicine, Kyung Hee University, Seoul 130-701, Republic of Korea. ${ }^{12}$ Department of Biotechnology, College of Biomedical and Health Sciences, Konkuk University, Chungju 380-701, Republic of Korea. ${ }^{13}$ Korea Association of Health Promotion, Seoul 157-928, Republic of Korea.

Received: 17 November 2013 Accepted: 4 December 2013 Published: 13 December 2013

\section{References}

1. Mendis K, Sina BJ, Marchesini P, Carter R: The neglected burden of Plasmodium vivax malaria. Am J Trop Med Hyg 2001, 64:97-106.

2. Hasegawa: Malaria in Korea. Chosen Igakkai Zasshi 1913, 4:53-69.

3. Progress report of National Malaria Eradication Service: Malaria pre-eradication programme in Korea, 1961-1965. Seoul: Ministry of Health and Social Affairs, Republic of Korea; 1966
4. Paik YH, Rhee HI, Shim JC: Malaria in Korea. Jpn J Exp Med 1988, 58:55-66.

5. Soh CT, Lee KT, Im Kl, Min DY, Ahn MH, Kim JJ, Yong TS: Current status of malaria in Korea. Yonsei Rep Trop Med 1985, 16:11-18.

6. Chai IH, Lim GI, Yoon SN, Oh WI, Kim SJ, Chai JY: Occurrence of tertian malaria in a male patient who has never been abroad. Korean J Parasitol 1994, 32:195-200.

7. Cho SY, Kong Y, Park SM, Lee JS, Lim YA, Chae SL, Kho WG, Lee JS, Shim JC, Shin HK: Two vivax malaria cases detected in Korea. Korean J Parasitol 1994, 32:281-284.

8. Lee JS, Lee WJ, Cho SH, Ree HI: Outbreak of vivax malaria in areas adjacent to the demilitalized zone, South Korea, 1998. Am J Trop Med Hyg 2002, 66:13-17.

9. Collins WE, Skinner JC: The indirect fluorescent antibody test for malaria. Am J Trop Med Hyg 1972, 21:690-695.

10. Wang DQ, Tang LH, Gu ZC, Zheng X, Yang MN: Application of the indirect fluorescent antibody assay in the study of malaria infection in the Yangtze River Three Gorges Reservoir. China. Malar J 2009, 8:199.

11. Curado I, Dos Santos Malafronte R, De Castro Duarte AM, Kirchgatter K, Branquinho MS, Bianchi Galati EA: Malaria epidemiology in lowendemicity areas of the Atlantic Forest in the Vale do Ribeira, São Paulo, Brazil. Acta Trop 2006, 100:54-62.

12. Cerutti C Jr, Boulos M, Coutinho AF, Hatab MC, Falqueto A, Rezende HR, Duarte AM, Collins W, Malafronte RS: Epidemiologic aspects of the malaria transmission cycle in an area of very low incidence in Brazil. Malar $J$ 2007, 6:33.

13. Lee JS, Kho WG, Lee HW, Seo M, Lee WJ: Current status of vivax malaria among civilians in Korea. Kor J Parasitol 1998, 36:241-248.

14. Arnot DE, Barnwell JW, Tam JP, Nussenzweig V, Nussenzweig RS, Enea V: Circumsporozoite protein of Plasmodium vivax: gene cloning and characterization of the immunodominant epitope. Science 1985, 230:815-818.

15. Lee HW, Lee WJ, Lee JS, Lee HS: DNA sequencing and expression of the Circumsporozoite protein of Plasmodium vivax Korean isolate in Escherichia coli. Korean J Microbiol 1999, 37:234-242.

16. General information of Ganghwa county. http://www.ganghwa.incheon. kr/open_content/main/we_ganghwa/introduction/present_condition.jsp.

17. Statistics of Cherwon county. http://www.cwg.go.kr/cheorwon/sub.html? menuKey $=230$.

18. Moody A: Rapid diagnostic tests for malaria parasites. Clin Microbiol Rev 2002, 15:66-78.

19. McKenzie FE, Prudhomme WA, Magill AJ, Forney JR, Permpanich B, Lucas C, Gasser RA Jr, Wongsrichanalai C: White blood cell counts and malaria. $J$ Infect Dis 2005, 192:323-330.

20. Na BK, Lee HW, Moon SU, In TS, Lin K, Maung M, Chung GT, Lee JK, Kim TS, Kong Y: Genetic variations of the dihydrofolate reductase gene of Plasmodium vivax in Mandalay Division, Myanmar. Parasitol Res 2005, 96:321-325

21. Lim KJ, Park JW, Sohn MJ, Lee S, Oh JH, Kim HC, Bahk YY, Kim YS: A direct sandwich ELISA to detect antibodies against the C-terminal region of merozoite surface protein 1 could be a useful diagnostic method to identify Plasmodium vivax exposed persons. Parasitol Res 2002, 88:855-860

22. Tsang VCW, Peralta JM, Simons AR: Enzyme-linked immunoelectrotransfer blot techniques (EITB) for studying the specificities of antigens and antibodies separated by gel electrophoresis. Meth Enzymol 1983, 92:377-391

23. Gao YH, Li HL, Lu Y, Gao FM, Lin YH, Zhou HC, Zhang LH, Wang H: Identification of a vaccine candidate antigen, PfMAg-1, from Plasmodium falciparum with monoclonal antibody M26-32. Parasitol Res 2009, 105:1723-1732.

24. Cohen J: Statistical power analysis for the behavioral sciences, 2nd ed. New Jersey: Lawrence Erlbaum Associate, Publishers; 1988.

25. Kim KC: Preserving biodiversity in Korea's demilitarized zone. Science 1997, 278:242-243

26. Shi YP, Alpers MP, Povoa MM, Lal AA: Diversity in the immunodominant determinants of the circumsporozoite protein of Plasmodium falciparum parasites from malaria endemic regions of Papua New Guinea and Brazil. Am J Trop Med Hyg 1992, 47:844-851.

27. Webster HK, Boudreau EF, Pang LW, Permpanich B, Sookto P, Wirtz RA: Development of immunity in natural Plasmodium falciparum malaria: 
antibodies to the falciparum sporozoite vaccine 1 antigen (R32tet32). J Clin Microbiol 1987, 25:1002-1008.

28. Kho WG, Jang JY, Hong ST, Lee HW, Lee WJ, Lee JS: Border malaria characters of reemerging vivax malaria in the Republic of Korea. Korean J Parasitol 1999, 37:71-76.

29. Lee WJ, Kim HH, Hwang SM, Park MY, Kim NR, Cho SH, In TS, Kim JY, Sattabongkot J, Sohn Y, Kim H, Lee JK, Lee HW: Detection of an antibody against Plasmodium vivax in residents of Gimpo-si, South Korea, using an indirect fluorescent antibody test. Malar J 2011, 31:10-19.

30. Snow RW, Gilles HM: The Anopheles vector. In Essential Malariology. 4th edition. Edited by Warrell DA, Gilles HM. London: Arnold; 2002:59-84.

Cite this article as: Cho et al:: Evaluation of circumsporozoite protein of Plasmodium vivax to estimate its prevalence in the Republic of Korea: an observational study of incidence. Malaria Journal 2013 12:448.

\section{Submit your next manuscript to BioMed Central and take full advantage of:}

- Convenient online submission

- Thorough peer review

- No space constraints or color figure charges

- Immediate publication on acceptance

- Inclusion in PubMed, CAS, Scopus and Google Scholar

- Research which is freely available for redistribution 